\title{
The role of learning technologists in supporting e-research
}

\author{
Susi Peacock*, Ann Robertson, Sarah Williams and Maria Giatsi Clausen \\ Centre for Academic Practice, Queen Margaret University, Queen Margaret University Drive, \\ Musselburgh, EH21 6UU, UK
}

(Received 11 May 2008; final version received 9 February 2009)

\begin{abstract}
This article explores how the role of learning technologists, a professional group that has emerged during the last 15 to 20 years, may be diversifying to include supporting e-research. It contributes to the current debate about the emerging profession and the roles it should play in contemporary higher education. Previous studies have shown that, typically, the profession's role has focussed almost exclusively on curriculum development; traditionally, learning technologists work with students and tutors to enhance the learning environment with technology. This article presents two case studies of $\mathrm{PhD}$ research that used a standard e-learning tool, the virtual learning environment (VLE), to conduct focus groups online. The case studies demonstrate the expert role of the learning technologist in supporting researchers to make informed decisions about whether and how to use e-learning tools to conduct qualitative e-research. The learning technologist advised on the potential advantages and limitations of using the VLE for research and fostered collaborative, working relationships with the researchers, acquiring extensive background knowledge about their projects. This required the learning technologist to draw upon her own experience with research into e-learning and on her professional experience gained from supporting curriculum developments. It is suggested that many learning technologists could extend their roles, transferring their knowledge to include supporting e-research. A more inclusive model of the learning technologist's role in academia could help address the potential polarisation of the profession into researchers and practitioners.
\end{abstract}

Keywords: learning technologists; e-research; online focus groups; e-learning tools

\section{Introduction}

Traditionally, the role of the learning technologist has been to "... provide a bridge between the technologies and the ways in which they can be used to support learning and teaching ..." (Conole, White, and Martin 2007, 79). In this paper, two case studies are presented which demonstrate a learning technologist playing an expert role in the support of academic e-research, drawing upon knowledge gained from supporting curriculum developments and prior e-learning research experience. This paper contributes to the current debate about the learning technology profession, and discusses perspectives on what constitutes a learning technologist, whether working in research and/or providing a support function.

*Corresponding author. Email: speacock@qmu.ac.uk 


\section{An emerging profession: the learning technologist}

Just as it is difficult to define educational technology, so it is almost impossible to identify an educational technologist. (Lawless and Kirkwood 1976, 54)

By the mid-1990s, a new and distinct category of learning support staff had emerged. New posts, for instance, of learning technology officer or web editor, were typically situated in staff development units, computing services or attached to a particular school, or faculty and post holders were usually responsible for embedding computer-aided learning (CAL) and information and communication technologies (ICT) (Atkins Report, HEFCE 1998). The creation of such posts was a response to:

- government policy drivers, including Dearing, which challenged higher education institutions (HEIs) to consider the potential for computers and information technologies (C\&IT) in the learning environment (NCIHE 1997);

- policy initiatives that had led to funding becoming available for short term projects, such as the Teaching and Learning Technology Programme (HEFCE, n.d.) and a number of Joint Information Systems Committee (JISC) projects. In 1997, the Higher Education Funding Council for England (HEFCE) estimated that $70 \%$ of all UK higher education institutions (HEIs) had some connection with an externally funded, learning technology programme (Beetham, Jones, and Gornall 2001); and

- the impact of the Internet on learning and teaching (Conole 2004).

These factors contributed to an increased awareness, especially amongst senior management, of the potential roles of technologies in the learning environment, accompanied by an emergence of strategies and policies that included e-learning (Conole, White, and Martin 2007). A few years after the Atkins Report, a national survey estimated there were 7500 learning technologists employed in the UK, of whom 4500 were found in central units and about 3000 in non-central locations (Beetham, Jones, and Gornall 2001). At this time, learning technologists could be divided into three groups:

(1) New specialists, such as educational developers. In most cases, these were individuals who were in their twenties or thirties and who had been in post for two years or less. Multi-skilled, they perceived learning technology to be their core skill. Almost all of the new specialists delivered some form of staff development through workshops, training courses and programmes.

(2) Academic and established professionals, including academic innovators. This group had typically developed an interest in, or had assumed responsibility for, learning technologies within an existing role in the institution. They were often older individuals who had been in post for a longer period than the new specialists.

(3) Librarians and technical staff, who supported learning technologies but who did not consider learning technology to be the main feature of their professional identities. Rather, learning technologies were "... the context in which they were now applying their professional skills" (Beetham, Jones, and Gornall 2001, 5). 
All learning technologists typically engaged with a wide range of diverse activities. Beetham, Jones and Gornall (2001) identified a total of 58 activities involved in the coordination, development, use and support of learning technologies. On average, some 20 of these were considered to be 'core' activities and a further 20 were secondary or occasional activities. These activities were categorised into 11 distinct roles. These roles included the learning technologist as:

- Educational developer;

- Educational researcher into learning technologies;

- Resource/materials developer;

- C\&IT skills professional;

- Library/resources professional;

- Technical support professional;

- Manager (teams and projects);

- Academic innovator; and

- Technical developer/researcher.

After the role analysis of 35 learning technologists, 23 institutional audits and 17 in-depth interviews, Beetham, Jones and Gornall (2001) reported that 75\% of their participants performed all 11 of the identified roles, at least on an occasional basis. Performing multiple roles required a significant range of skills and knowledge and: "... competence in an extraordinarily wide range of areas" (Beetham, Jones, and Gornall 2001, 5). The learning technologist tended to be involved: “... in the entire process of learning technology development, support and use, rather than in a specific part of the process" (Beetham, Jones, and Gornall 2001, 31). For further information about this study, see Conole (2004).

A study by Oliver (2002) provided further insights into one of the groupings identified by Beetham, Jones and Gornall (2001): the new specialists. Amongst this group, Oliver (2002) identified:

- An interest in pedagogy rather than technology. This group believed the focus of its role was to improve the learning environment for staff and learners. One participant said: "I would categorize a bad learning technologist as someone who is a geek ... somebody who is totally involved with the software and hardware products and wasn't interested in establishing relationships" (Oliver 2002, 249).

- Working collaboratively with academics. Typically, the new specialists worked on curriculum development activities in collaboration with individual or small groups of academics. According to Oliver (2002): “... the learning technologist must invest considerable time in building goodwill and strong collaborations across the institution, and relies on their specialist expertise and rhetorical skills to influence developments and decision making" (249).

- A diversity of roles. New specialists typically performed a wide array of activities, ranging from staff development and technical support to management and research.

More recently, Conole (2004) and Conole, White and Martin (2007) have highlighted a potential 'bipolarisation' of learning technologists into more specialist roles. Some learning technologists focus on research, and are situated within 
research centres, and others focus on providing a support function and are situated in support department or units. Conole (2004) characterises the research learning technologists as being:

- focused on research questions about learning technology;

- enthused by the 'traditional research drivers', such as funding for research grants; and

- in many cases, not directly involved with the practical application of learning technologies.

In comparison, learning technologist practitioners are described as being:

- focused on using e-learning effectively in the institution;

- concerned about implementing e-learning research findings in their particular, institutional contexts; and

- immersed in institutional politics.

According to Conole, White and Martin (2007), these emerging, specialist groups do not appear to network with each other but prefer to build links within their own group or with other specialists. For example, a learning technologist researcher would network with a cognitive psychologist rather than a learning technologist practitioner. Such a movement towards learning technologists specialising in either research or practice could be linked to Chartrand's notion of the distinctions to be drawn between science and the arts; researchers, with a scientific perspective, develop and advance scientific knowledge whilst practitioners, generally more inclined towards the arts, develop professional skills through practical application (Conole 2004; Conole, White, and Martin 2007).

Any polarisation of learning technologists into researchers and practitioners might be viewed as a second phase in the emergence of the profession. It represents a recent move away from the wide-ranging, multi-faceted roles of the first learning technologists (Conole, White, and Martin 2007). If specialist roles within the profession were to become established, it would bring with it certain challenges. Such challenges might include:

- the possible fragmentation of the learning technologist profession;

- the possibility of a hierarchy developing within the profession, perhaps with the increased status of those undertaking research; and

- the possibility of a lack of constructive dialogue between two, specialist groupings inside the profession.

The latter could impact adversely on the profession's progression in a number of ways. For instance, if practitioners are not fully aware of the latest, e-learning research findings that will limit the implementation of evidence based practice. Simultaneously, if researchers are not well informed about current issues and limitations in learning technology practice, opportunities for research to bring 'real world' benefits to practitioners will be lost (Conole, White, and Martin 2007).

An alternative to wide spread specialisation amongst learning technologists is, however, possible. It is proposed that learning technology posts should be viewed on a spectrum, with the expert practitioner at one extreme and the specialist researcher at 
the other. Most learning technologists retain their traditional, broad range of diverse skills and are located somewhere 'in the middle', with many undertaking some elearning research and using that research to inform their practice. In addition, the role of these multi-skilled learning technologists could include supporting e-research being undertaken by researchers within their institutions. It is only recently that academics from other disciplines have asked learning technologists to support them in the use of e-learning tools to conduct qualitative, academic research (Kenny 2005). Clearly, the different activities with which individual learning technologists engage will relate to the particular needs of their institutions and to their own skills, interests and experience.

An example of the proposed model follows, with an account of the way in which one university-based learning technologist expanded her multi-skilled role to include providing individual professional support to $\mathrm{PhD}$ students conducting qualitative eresearch. The learning technologist is 'a well-established new specialist' within a central support department with a multi-functional role, covering all 11 of the roles identified by Beetham, Jones and Gornall (2001). Her core identity is a learning technologist. She has managerial responsibilities; collaborates with academics on a daily basis to implement e-learning within the learning environment - for which she draws on research from within and outside learning technology; and undertakes limited, small-scale research, usually in collaboration with a subject specialist.

\section{Using a virtual learning environment to support e-research}

E-research, including web-based surveys, questionnaires, experiments and e-interviews, is now commonplace, reflecting how pervasive the Internet has become (Denscombe 2003). This section describes how e-learning tools in a virtual learning environment (VLE) (WebCT) were used to support the qualitative research method of online focus groups and discusses the expert role of the learning technologist in supporting the research process. An online focus group (OFG) refers to a selected group of individuals who have volunteered to participate in a moderated, structured, online discussion in order to explore a particular topic for the purpose of research.

\section{Two case studies using a VLE to support online focus groups}

Case study 1: occupational therapists' (OTs) perceptions of pre term children's academic difficulties in the early years of mainstream schooling

This study sought to explore:

- views of OTs on the difficulties encountered by mainstream school children who had been born prematurely;

- criteria used when clinicians select specific assessment and intervention procedures for this paediatric population;

- participants' perceptions of the importance of occupational therapy in Early Intervention Services; and

- factors that inform everyday decision-making by OTs in clinical practice.

Two, asynchronous OFGs were conducted to collect data in a three stage, mixed methods study. Thirteen participants, who had previously completed a questionnaire and who had volunteered to take part in the subsequent OFGs, were allocated to one 


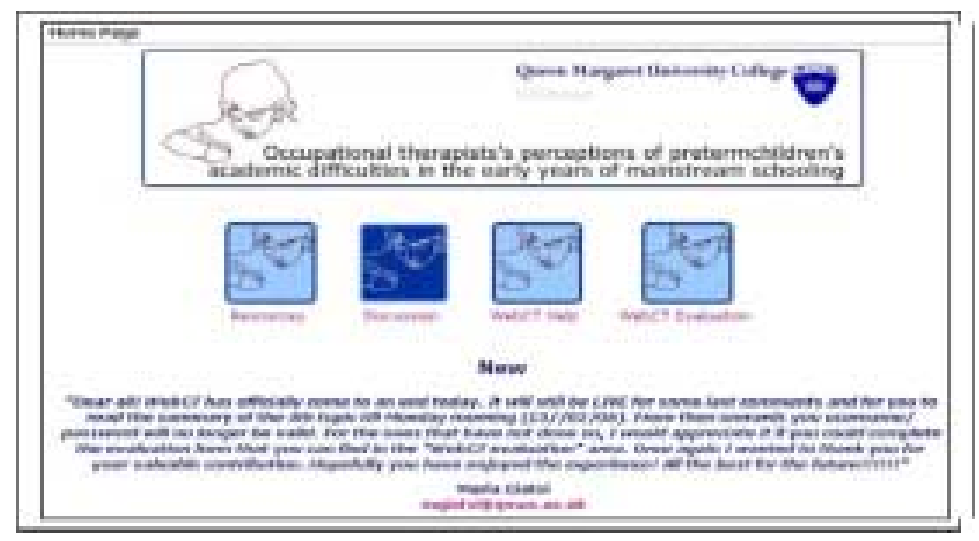

Figure 1. The WebCT homepage for case study 1.

of the two discussion groups (see Figure 1). The OFGs were employed to gain deeper understanding of issues stemming from the analysis of the questionnaire data. OFGs were chosen specifically because of the difficulties of physically bringing together a small group of geographically dispersed, specialist OTs. The OFGs ran for one month.

Case study 2: understanding anorexia nervosa: the maintainer's perspective.

Twelve participants were recruited from pro-anorexic websites to identify how those wishing to maintain anorexic behaviours experienced and understood their disorder and treatment. Pro-anorexic websites typically include online forums for site visitors to communicate with one another; an OFG was chosen to collect data because this method emulated the online situations to which participants were accustomed. Before the OFG, participants filled in two questionnaires, which measured participant demographics, attitudes to anorexia and eating disorder psychopathology. This was part of the data collection process but also allowed the researcher to screen participants for suitability for the study. This OFG was also asynchronous and it ran for a total of five weeks.

In both cases, the OFGs generated rich, qualitative data for analysis for $\mathrm{PhD}$ theses. Our case studies show that e-learning tools, such as a conventional, institutionally or departmentally hosted VLE, can be successfully used to support asynchronous, qualitative e-research (see Figures 2 and 3). They also demonstrate a non-traditional role for the learning technologist in supporting e-research.

\section{The learning technologist's role in the case studies}

Working with the $\mathrm{PhD}$ students on an individual basis (mirroring the format of working with tutors on curriculum development), the learning technologist's role was to outline to the researchers the potential of the VLE for conducting online research. Having conducted face to face $(\mathrm{F} 2 \mathrm{~F})$ focus groups during her own research into e-learning, the learning technologist was able to discuss creating a customised online environment that would be appropriate for each researcher's project. The venue for a F2F focus 


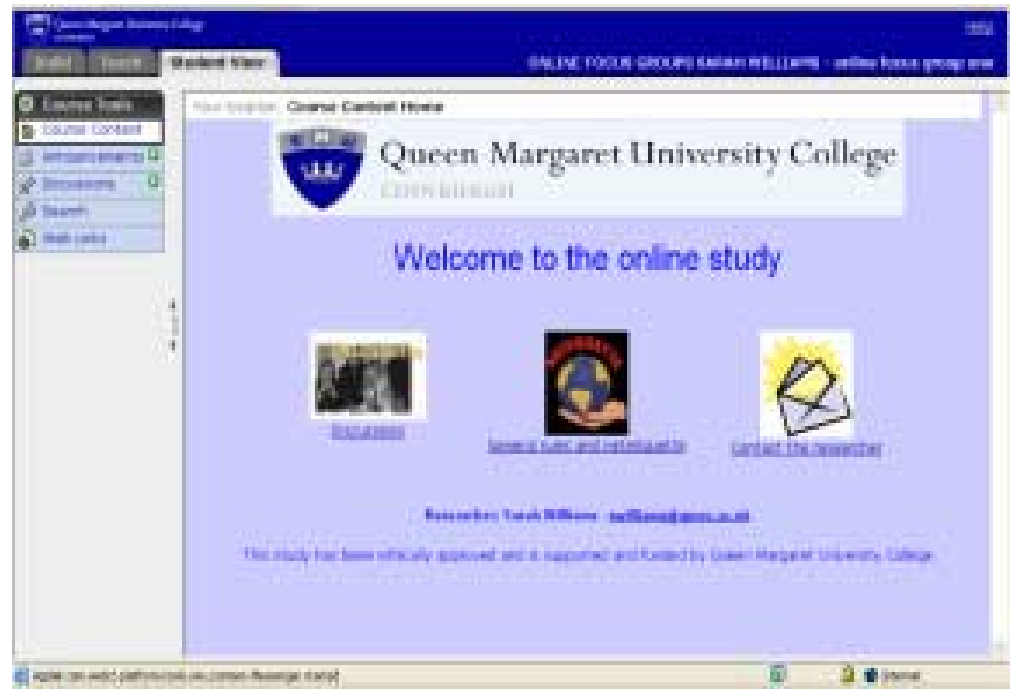

Figure 2. The WebCT homepage for case study 2.

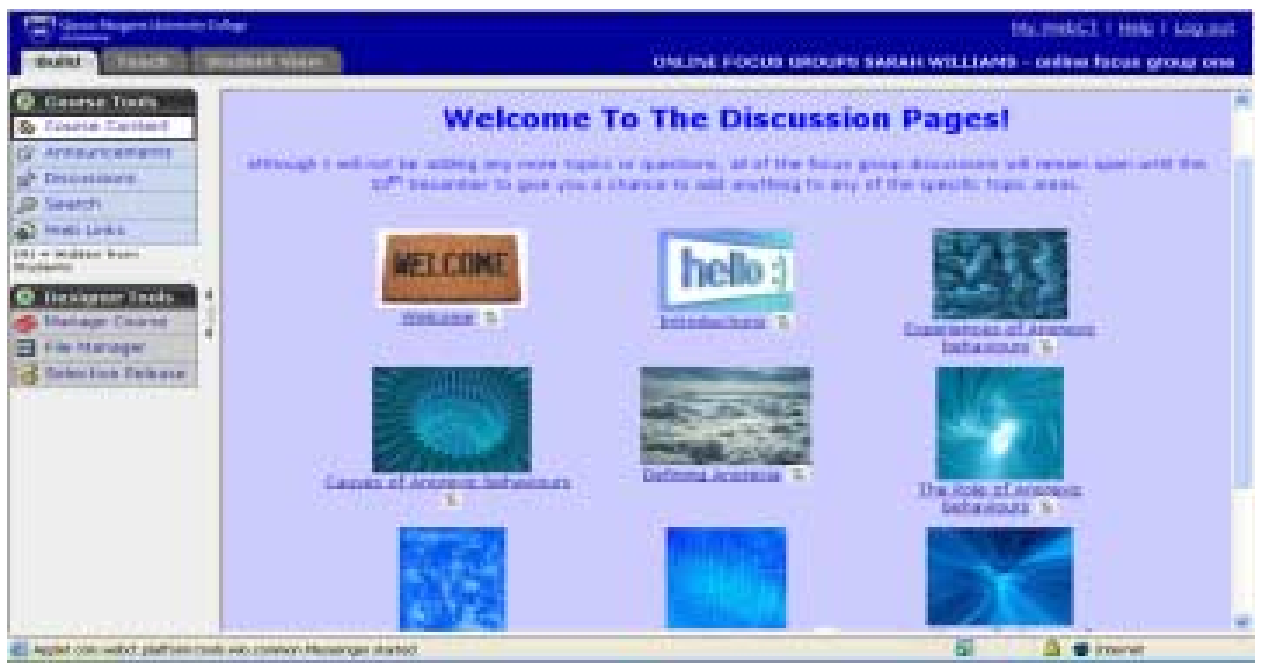

Figure 3. The discussions page for case study 2 .

group is a key consideration for a researcher (Mann and Stewart 2000). It needs to be easy for participants to find, free of distractions, relaxed, informal and quiet (Kreuger and Casey 2000). The learning technologist discussed the ways in which a suitable focus group environment could be developed online using the VLE.

The learning technologist next described how the discussion tool within the VLE could be used for collecting research data. This entailed explaining about the setting up and structuring of discussion areas, the use of welcome messages, threading messages and ways in which to elicit responses. She provided guidance on 'net etiquette' and explained how to transfer OFG postings from the VLE into Microsoft Word. The learning technologist drew upon her own experience of using online 
discussion groups (ODGs) for supporting blended learning. Through these individual meetings with the researchers, the learning technologist began to develop a collaborative working relationship with them, similar to those created when working with academics for curriculum developments as described by Oliver (2002).

Learning technologists draw upon pedagogical and technological knowledge, previous experience of e-learning and examples from research to facilitate curriculum developments. In addition, they have a common language with academic tutors, through which the parties can conduct meaningful discourses when working together. Similarly, it was necessary for the learning technologist to gain an understanding of the particular method of qualitative e-research being used by the $\mathrm{PhD}$ researchers in order to develop a common language and to communicate effectively with them. Therefore, the learning technologist had to develop a wider and more in-depth knowledge of F2F focus groups and OFGs. Frequently, she found the researchers would refer to current work in the field of OFGs and ask the learning technologist for further examples. Throughout the process of supporting their OFG research, the learning technologist collated examples of how OFGs had been used by other researchers and outlines of three prior OFG studies are presented in Table 1 (a more extensive list was developed). This table is similar to materials developed by the learning technologist to provide exemplars and case studies for tutors considering adopting e-learning tools in the curriculum.

The learning technologist also had to become conversant with the terminology associated with online, qualitative research. There is some ambiguity in the literature about the different types of discussion groups in the online environment, such as synchronous and asynchronous OFGs and online forums (Murray 1997; Turney and Pocknee 2005; Adler and Zarchin 2002; Sweet 2001). For clarity, it was necessary for the learning technologist in association with the researchers to develop a table (see Table 2) defining the terms they used and differentiating OFGs from other online groups.

The learning technologist was expected to have a thorough understanding of the advantages and challenges of using OFGs from the perspective of the researchers and drew upon her own experience of supporting e-tools for curriculum development. Advantages of OFGs include savings on time, travel and transcribing. Further, an OFG allows research participants to be drawn from different time and geographical zones (Oringderff 2004) and from diverse populations, some of whom are typically difficult to reach, such as those who:

- have limited physical mobility (Turney and Pocknee 2005);

- are housebound (Denscombe, 2003), including people who are ill, such as patients in the later stages of cancer (Im and Chee 2006) and pregnant women on enforced bed rest (Adler and Zarchin 2002);

- are in dangerous or politically sensitive areas (Mann and Stewart 2000).

OFGs may also facilitate research with busy professionals who might not otherwise be available to participate in a study (Boshoff, Alant, and May 2005). Learning technologists will frequently cite similar advantages when advising tutors about the benefits of ODGs for reaching out to distance and part-time learners.

When advising the researchers about potential disadvantages of OFGs, again, the learning technologist drew on experience gained through using ODGs for learning and teaching. For example, the inability of an online researcher to interact personally, 
Table 1. A brief overview of studies using online focus groups (OFGs).

Im, E. and W. Chee. 2006. An online forum as a qualitative research method. Nursing Research 55, no. 4: 267-73.

Im and Chee discuss online research undertaken into the cancer pain experience of four, major, ethnic groups in the US over a six-month period. They provide detailed information about data analysis and the OFGs, which they refer to as online forums. They discuss the advantages and disadvantages of OFGs, e.g. credibility. Since the study produced a high response and retention rate, with $86 \%$ of participants posting for the six-month period, the data were credible but the researchers were aware that non-verbal cues were missing from the transcripts. They discuss issues of dependability, transferability and security. An excellent discussion of methodology issues in moving the focus group online.

$N=$ c. 30 for each OFG.

Subject area: nursing - cancer pain experience of four ethnic groups

Terminology: asynchronous online forums

Technology: four closed Internet groups held on project server

Used in conjunction with an Internet survey

Kenny, A. 2005. Interaction in cyberspace: an online focus group. Methodological issues in nursing research. Journal of Advanced Nursing 49, no. 4: 414-22.

Kenny describes the use of a VLE (WebCT) to support an asynchronous OFG over a twomonth period with 38 Australian Enrolled Nurses, where 263 posting were made to the OFG. She discusses the methodological and ethical implications of moving the focus group online and the practical advantages of using the OFG as a research tool, such as including participants in different locations, reduced cost, an extended time to pose questions and explore the topic and group control. Other issues considered include participant anonymity and computer access.

$N=38$

Subject area: nursing - attitudes to distance learning

OFG: asynchronous online focus groups

Technology: VLE

Stewart, F., E. Eckermann, and K. Zhou. 1998. Using the internet in qualitative public health research: A comparison of Chinese and Australian young women's perceptions of tobacco use. Internet Journal of Health Promotion. http://www.rhpeo.org/ijhp-articles/1998/12/index.htm

A brief overview of Internet research is provided and, although somewhat dated, it covers areas that need to be considered when moving the F2F focus group online. It also outlines attitudes to tobacco in Australia and China. The research used synchronous OFGs. For two hours, participants from both Australia and China were asked to discuss in pairs their attitudes to tobacco. The authors describe the main results and the interactions between the participants. The authors compare the findings from two F2F focus groups and the OFGs and highlight issues when deploying a synchronous OFG.

$N=8$

Subject area: public health - attitudes to tobacco of Australian and Chinese young women Terminology: synchronous virtual focus groups

Technology: institutional online chat tool: First Class

Exploratory study: two F2F focus groups (one in China and one in Australia) followed by four synchronous OFGs

face-to-face (F2F) with group members and thereby build F2F rapport (Greenbaum 2002) may be a disadvantage of using OFGs; a criticism of ODGs is that online tutors may find it difficult to develop appropriate relationships with their students. The researchers carrying out the case studies wanted to know if there were advantages specifically of using an institutionally based learning and teaching tool for research, 
Table 2. Clarification of terminology associated with online, group communication.

It may be useful to differentiate OFGs from other online applications, such as online discussion groups, online support groups and online forums. All of these have a similar purpose - group communication around a particular topic - but there are differences between them, which are outlined below:

Online discussion groups (ODGs) are used to enhance the learning environment. Learning technologists will be familiar with supporting tutors and students who are using ODGs and will typically call upon the work of Salmon (2003) to support this;

Online support groups (OSGs), sometimes also referred to as Internet Support Groups (ISGs), offer information and support to people who share a similar situation or problem. These may be professionally run or led by private individuals and provide an opportunity for people to discuss, for example, experiences of physical and mental health problems;

Online forums (OFs) are open, Internet groups for discussing topics of general interest. An OF is run by an administrator who has an interest in that topic area. Confusion may be caused by researchers sometimes referring to OFs for what would here be considered to be OFGs (Im and Chee 2004). The OFG, unlike the OF, is researcher driven, with participants purposively selected for their personal knowledge about the topic under investigation. OFG discussions are developed from questions set by the researcher, who is aiming to collect sufficient data to illuminate a research question.

especially in their duty of care to their participants. The learning technologist therefore discussed with them the ways in which the VLE could provide a (1) secure, (2) confidential and (3) safe environment for research participants.

\section{(1) A secure online environment}

The learning technologist described the security measures applied by the information technology (IT) department, which would impact on the security of the online environment. At Queen Margaret University (QMU), like most institutions, the IT department has adopted a 'depth in defence' approach (Hansche, Berti, and Hare 2004), ensuring that security measures are applied at different levels of the technical environment. For example, at the server level, the latest security patches are applied regularly, after compatibility testing, and anti-virus software updates are installed whenever a new signature is released. Web servers, like the VLE, use Secure Socket Layer (SSL) to encrypt passwords and data on each separate page. Such security procedures provided some confidence to the researchers that there would not be unwanted intrusion into their research areas on the VLE, for example, by hackers.

Further advice was provided about the institution's archiving and deletion policy for research data. This enabled the researchers to explain to their participants how long and in which format the research data would be kept, and how it would be disposed of. At QMU, as in many other institutions, research data are kept for five years after the research has finished. The OFGs created in the VLE will be retained for this period in the archive of the e-learning tool, which is kept off site in a secure location (Queen Margaret University 2007).

\section{(2) A confidential, password-protected, online environment}

The learning technologist was able to provide information about account creation in the VLE and thereby reassure the researchers about participant confidentiality. For 
case study 2, it was of particular importance for participant safety that no uninvited, unscreened participants could enter the research area; it was important that any person disagreeing with pro-anorexia could not access the site and insult participants. The learning technologist was able to cite examples in which open Internet discussion groups had been used for e-research that had been jeopardised by uninvited individuals seeking public visibility for their views, such as was experienced in a study by Adams, Rodham and Gavin (2005).

\section{(3) A safe online environment}

Drawing upon her experience with using ODGs in the learning environment, the learning technologist discussed with the researchers the importance of having guidelines and ground rules for the OFG participants. Consequently, prior to joining an OFG, participants in both case studies were provided with written guidelines about the types of postings that would or would not be acceptable: a net etiquette guide (Oringderff 2004). This covered the content, style and tone of messages that would be appropriate for the OFG. All participants were also informed that if an inappropriate posting was made, it would be removed by the researcher. The learning technologist ensured that the researchers, who moderated their own sites, knew the procedures for deleting accounts or postings if this should become necessary during their studies. Such ground rules were of particular importance in case study 2 because participants were recruited from pro-anorexic websites where visitors can find, and contribute to, information to aid the maintenance of anorexia. It was vital that participants did not provide information to other OFG members that would further encourage anorexic behaviours.

Discussions between the learning technologist and each researcher also focussed on the limitations of using a VLE, for example:

- ownership of the e-learning tool. As the VLE is hosted by an institution/department, unlike a discussion board hosted on the Internet, the e-learning tool is accessible to authorised support staff within the institution/department. In the case studies, both researchers and participants relied on a VLE administrator and IT network manager to adhere to a professional code of conduct and not to access the OFGs.

- Freedom of Information (FoI) requests. Since January 2005, the Freedom of Information (Scotland) Act 2002 has sought to increase openness and accountability across the public sector by ensuring there is access to information held by Scottish public authorities. Academic institutions are therefore open to answering FoI requests regarding the research they are undertaking. As research data from OFGs are recorded and held by the university on the VLE, a FoI request could be made for the release of information held in an OFG. At QMU, it has been agreed that if such requests were to be received, they would be judged on a case by case basis.

\section{Learning technologists: a diverse and diversifying profession}

The case studies illustrate a learning technologist supporting individual researchers to undertake qualitative research using e-learning tools. The expert role played by the learning technologist in supporting e-research is different from the traditional role of 
supporting curriculum developments but similar in style to the ad hoc tutoring role outlined by Oliver (2002). Initially, the researchers sought information about the type of technology that could be used to support their research but the learning technologist's role developed into providing information, advice and practical support for employing e-learning tools to conduct the research. It is suggested that many learning technologists could similarly collaborate with academic e-researchers because:

- learning technologists often have some experience of conducting research themselves, for example in e-learning, and many would like to continue to do so (Beetham, Jones, and Gornall 2001);

- much of the research support provided in the case studies drew upon the learning technologist's experience of using e-learning tools in the learning environment; and

- they are usually well qualified to do so: a significant number of learning technology posts require a Master's degree as a minimum, if not a $\mathrm{PhD}$ (Surry and Robinson 2001).

The diversification of the learning technologist's role described in the case studies is related to questions about the possible polarisation of the learning technology profession. Undoubtedly, there are now some full time, e-learning researchers who focus exclusively on learning technology research. However, most of the 7500 learning technologists are still multi-functional, as indicated in the study by Oliver (2002); these learning technologists may be involved with research to some extent, especially if working in research led institutions. With the increasing diversification of other roles in academia, in addition to the growing popularity of e-research, it seems likely that many learning technologists' positions will remain - or even become more diverse in future (Conole, White, and Martin 2007). As Conole (2004) states, the inter-disciplinary nature of learning technologies naturally leads to diversity.

It may therefore be timely to focus on strengthening the profession by seeking to establish an overarching set of professional values, which emphasise collaboration within and outside the profession while supporting learners and staff to make more effective use of learning technologies. Establishing agreed values would start to bridge the growing gap between learning technologist practitioners and e-learning researchers, which was noted by Conole (2004). In addition to the values identified by Oliver (2002), the study by Beetham, Jones and Gornall (2001) should be considered, in which core values of 'new specialists' included:

- a strong focus on quality student learning;

- a positive orientation to change;

- belief in collegiality and team work; and

- commitment to building networks and working across boundaries.

Alternatively, Rieber (1998) provided a list of statements about a learning technologist:

- I help people learn new things;

- I solve problems in education and training, or find people who can;

- I use lots of different tools in my job; some are 'things' like computers and video, other tools are ideas, like knowing something about how people learn and principles of design; 
- I resist doing things only because 'we've always done it that way', but I am also careful not to fall for fads or gimmicks.

Finally, it is important that learning technologist practitioners who wish to engage with research should be actively supported to do so. Beetham, Jones and Gornall (2001) reported that learning technologists were often keen to undertake academic research or study, however, many were "spread too thinly" (Oliver 2002) and would find it difficult to balance the needs of their support role with carrying out research: "You kind of want to do research and produce papers and so on but at the same time you're not in an academic post, you're in a support one" (Beetham, Jones, and Gornall 2001, 56).

\section{Conclusion}

E-research is becoming commonplace and seems certain to increase in the next decade. Our case studies demonstrate it is feasible to use e-learning tools to collect a wealth of rich, qualitative data in OFGs. Simultaneously, e-learning tools are becoming more sophisticated (especially Web 2.0 tools) and such tools have the potential to support qualitative research in many subject areas across an institution. As a result, learning technologists in the future are likely to be asked to provide expert support for the use of e-learning tools by researchers. Milstead and Nelson (1998) argue that universities should support e-research and that this support must go beyond offering basic technical support if academics are to carry out e-research effectively. According to Duffy (2000), there has been a lack of institutional support for those conducting Internet studies.

In our case studies, however, researchers using the VLE could call upon the learning technologist for individual expert advice and assistance. This role was outside the learning technologist's existing roles, which were predominantly associated with supporting curriculum developments (the traditional support role). Nonetheless, an eresearch support role is within the scope of most learning technologists, many of whom are also accustomed to carrying out a diverse range of activities in their posts and are used to transferring their knowledge from one situation to another. This paper proposes that rather than endorsing the 'bipolarisation' of learning technologists into practitioners or researchers, we should view multi-skilled posts within the profession as a strength, with a set of core values held in common by all that work in a diverse profession. Learning technologist practitioners who wish also to engage with research should be supported to do so. It is hoped that such an inclusive approach may encourage institutions to recognise fully the significant contributions already made by para-academics and to capitalise further on the potential contributions of learning technologists. This paper seeks to contribute to current debate about the learning technology profession and hopes that it will encourage more research into this emerging role.

\section{Acknowledgements}

The authors would like to thank all the participants of the OFGs and Professor Marie Donaghy, Dr Jan Gill, JISCLegal, Valerie McKeown, Dr Kerri McPherson, Dr Kate Morss, Professor Maggie Nicol, Dr Martin Oliver, Norman Phipps, Professor Marie Reid, Dr Pat Roche, Jamie Tait, Mark Toole and Dr Joyce Willock and the reviewers for ALT-J. 


\section{References}

Adams, J., K. Rodham, and J. Gavin. 2005. Investigating the 'self' in deliberate self-harm. Qualitative Health Research 15, no. 10: 1293-309.

Adler, C., and Y. Zarchin. 2002. The 'virtual focus group': Using the internet to reach pregnant women on home bed rest. Journal of Obstetric, Gynecologic and Neonatal Nursing 31, no. 4: 418-27.

Beetham, H., S. Jones, and L. Gornall. 2001. Career development of learning technology staff: Scoping study final report. JISC Committee for awareness, liaison and training programme. http://www.jisc.ac.uk/publications/publications/cdssfinalreport.aspx

Boshoff, K., E. Alant, and E. May. 2005. Occupational therapy managers' perceptions of challenges faced in early intervention service delivery in South Australia. Australian Occupational Therapy Journal 52: 232-42.

Conole, G. 2004. The role of learning technology practitioners and researchers in understanding networked learning. Networked learning conference 2004. http://www.networkedlearningconference.org.uk/past/nlc2004/proceedings/symposia/symposium $1 /$ conole.htm

Conole, G., S. White, and O. Martin. 2007. The impact of e-learning on organisational roles and structures. In Contemporary perspectives in e-learning research, ed. G. Conole and M. Oliver, 69-81. Abingdon, UK: Routledge.

Denscombe, M. 2003. The good research guide for small-scale social research projects. Maidenhead, UK: OUP.

Duffy, M. 2000. Web-based research: An innovative method for nursing research. Canadian Oncology Nursing Journal 10, no. 2: 45-9.

Freedom of Information (Scotland) Act. 2002. http://www.opsi.gov.uk/legislation/scotland/ acts2002/asp_20020013_en_1

Greenbaum, T. 2002. The case against internet focus groups. MRA Alert Newsletter. http:// www.groupsplus.com/pages/case2.htm

Hansche, S., J. Berti, and C. Hare. 2004. Official (ISC) 2 guide to the CISSP exam. Boca Raton, FL: CRC Press.

Higher Education Funding Council for England (HEFCE). n.d. Teaching and Learning Technology Programme (TLTP). http://www.hefce.ac.uk/Learning/tinits/TLTP/

Higher Education Funding Council for England (HEFCE). 1998. An evaluation of the Computers in Teaching Initiative and Teaching and Learning Technology Support Network: The Atkins report. http://www.hefce.ac.uk/pubs/hefce/1998/98_47.htm

Im, E., and Chee, W. 2006. An online forum as a qualitative research method. Nursing Research 55, no. 4: 267-73.

Kenny, A. 2005. Interaction in cyberspace: An online focus group. Methodological issues in nursing research. Journal of Advanced Nursing 49, no. 4: 414-22.

Kreuger, R., and M. Casey. 2000. Focus groups: A practical guide for applied research. Thousand Oaks, CA: Sage.

Lawless, C., and A. Kirkwood. 1976. Training the educational technologist. British Journal of Educational Technology 1, no. 7: 54-60.

Mann, C., and F. Stewart. 2000. Internet communication and qualitative research: A handbook for researching online. London: SAGE.

Milstead, J., and R. Nelson. 1998. Preparation for an online asynchronous university doctoral course: Lessons learned. Computers in Learning 16, no. 5: 247-58.

Murray, P. 1997. Using virtual focus groups in qualitative research. Qualitative Health Research 7, no. 4: 542-9.

The National Committee of Inquiry into Higher Education (NCIHE). 1997. The Dearing Report. http://www.leeds.ac.uk/educol/

Oliver, M. 2002. What do learning technologists do? Innovations in Education and Training International 394, no. 4: 245-52.

Oringderff, J. 2004. 'My way': Piloting an online focus group. International Journal of Qualitative Methods 3, no. 3. http://www.ualberta.ca/ iiqm/backissues/3_3/html/ oringderff.html

Queen Margaret University. 2007. Records management policy. http://www.qmu.ac.uk/foi/ docs/Records\%20management \%20policy\%20final.doc

Rieber, L. 1998. The proper way to become an instructional technologist. ITFORUM paper 24. http://it.coe.uga.edu/itforum/paper24/paper24.html 
Salmon, G. 2003. E-moderating: The key to teaching and learning online. London: Routledge Falmer.

Sweet, C. 2001. Designing and conducting virtual focus groups. Qualitative Market Research: an International Journal 4, no. 3: 130-5.

Surry, D., and M. Robinson. 2001. A taxonomy of instructional technology service positions in higher education. Innovations in Education and Teaching International 38, no. 3: 231-8.

Turney, L., and C. Pocknee. 2005. Virtual focus groups: new frontiers in research. International Journal of Qualitative Methods 4, no. 2: 32-43. 